\section{Doubled Haploid Inbred Lines USVL048 and USVL131 of Heading Broccoli}

\author{
Mark W. Farnham ${ }^{1,2}$ \\ U.S. Department of Agriculture, Agricultural Research Service, U.S. Vegetable \\ Laboratory, 2700 Savannah Highway, Charleston, SC 29414
}

Additional index words. Brassica oleracea-Italica group, doubled haploids, cole crops, anther culture

Two inbred lines of heading broccoli (Brassica oleracea L. var. italica), designated USVL048 and USVL131, were released by the Agricultural Research Service of the U.S. Department of Agriculture in 2012. Both of the released lines are doubled haploids originally derived from anther cultures. As doubled haploid broccolis, both USVL048 and USVL131 are uniform, homozygous, truebreeding inbred lines. In addition, they both produce heads with high-quality characteristics. USVL048 and USVL131 can be readily crossed with other broccoli inbreds to make new hybrid combinations for direct use or for generating new segregating populations.

\section{Origin}

The broccoli breeding program at the U.S. Vegetable Laboratory (Charleston, SC) has developed a large number of doubled haploid lines of broccoli using anther culture (Farnham, 1998; Farnham et al., 1998). All such doubled haploid lines are highly uniform and can be presumed to be homozygous. Both USVL048 and USVL131 are doubled haploid lines regenerated from anther cultures at the U.S. Vegetable Laboratory. Each line originated from a different and unique $\mathrm{F}_{1}$ parent that served as a source of anthers for the starting cultures.

USVL048 was derived from anther culture of the commercial hybrid 'Marathon'. The original doubled haploid was regenerated from culture in late summer 1995, moved to a pot in a greenhouse, and self-pollinated to produce seed (Fig. 1). The parental hybrid 'Marathon' is fertile and heterozygous, and produces a segregating population when selfpollinated. Conversely, USVL048 is an inbred, homozygous line as is expected for a doubled haploid. USVL048 is partially self-compatible and will produce some seed without manual pollinations; however, to maximize seed production of this line, it is recommended to use self-pollination techniques (e.g., bud

\footnotetext{
Received for publication 7 Mar. 2013. Accepted for publication 4 May 2013.

${ }^{1}$ Research Geneticist.

${ }^{2}$ To whom reprint requests should be addressed; e-mail Mark.Farnham@ars.usda.gov.
}

pollinations) that are standard for producing Brassica seed.

USVL131 was regenerated from anther culture of a U.S. Vegetable Laboratory hybrid $\left(\mathrm{F}_{1}\right)$ formed by crossing a 'Viking'-derived doubled haploid line with an 'Everest'-derived doubled haploid line. As done with USVL048, the original doubled haploid plant regenerated from culture in 1999 was moved to a pot in a greenhouse and then self-pollinated to produce seed (Fig. 1). Again, as expected for doubled haploids, USVL131 is a homozygous inbred line that breeds true. USVL131 is more self-incompatible than USVL048, and it produces very little seed without manual pollinations. Seed production of this line can be maximized by conducting bud self-pollination.

\section{Description}

USVL048 and USVL131 are among the latest maturing lines grown in the U.S. Vegetable Laboratory broccoli program. USVL048 is the latest to mature of the two lines, maturing in $\approx 90$ to $100 \mathrm{~d}$ after transplanting in an optimal southeastern U.S. fall (September through December) environment. This maturity is very similar to the commercial broccoli hybrids 'Marathon' and 'Legacy'; however, USVL048 is typically later (Table 1). USVL048 initiated in 1995. produces high-quality broccoli heads that have comparable quality to commercial hybrids like 'Liberty', 'Patron', and 'Gypsy' (Table 1). The weight of typical heads produced by this line is often comparable to that of hybrids when grown in the same trials with heads cut to a 6-inch length usually weighing $\approx 170$ to $200 \mathrm{~g}$. Other head traits of USVL048 include a high dome shape, intermediate bead size (ranging from 1.45 to $1.65 \mathrm{~mm}$ ), and a stem diameter of 28 to $32 \mathrm{~mm}$ (Table 1). USVL048 has intermediate vigor and a high degree of uniformity in field trials (Fig. 2).

USVL131 can mature up to $10 \mathrm{~d}$ earlier than USVL048, i.e., $\approx 85 \mathrm{~d}$ after transplanting in optimal fall environments (Table 1). Typically, it matures after the commercial hybrids 'Liberty' and 'Patron' but before 'Marathon' and 'Legacy'. USVL131 also produces high-quality broccoli heads that have comparable quality to commercial hybrids like 'Patron', 'Gypsy', and 'Captain' (Table 1). Head weights for this line were comparable to those for hybrids grown in the same trials; the weight range of heads cut to a 6-inch length is usually 180 to $220 \mathrm{~g}$. USVL131 also has a high dome shape that is comparable to that exhibited by 'Liberty' and 'Marathon'. Other head traits of this line include small to intermediate bead size ( 1.40 to $1.60 \mathrm{~mm}$ ) and stem diameters ranging from 30 to $32 \mathrm{~mm}$. USVL131 has intermediate vigor and a high degree of uniformity in field trials similar to USVL048 (Fig. 2).

USVL048 has been used extensively as a tester line for making hybrid combinations in the U.S. Vegetable Laboratory breeding program. Harvested heads of USVL048 have been shown to exhibit relatively high levels of glucoraphanin (Farnham et al., 2004). In addition, USVL048 exhibits a positive general combining effect for glucoraphanin concentration (Abercrombie et al., 2005). USVL048 has also been shown to confer significant heterosis or hybrid vigor for several horticultural traits when it is crossed with other inbreds to make $\mathrm{F}_{1}$ hybrids (Hale et al.,

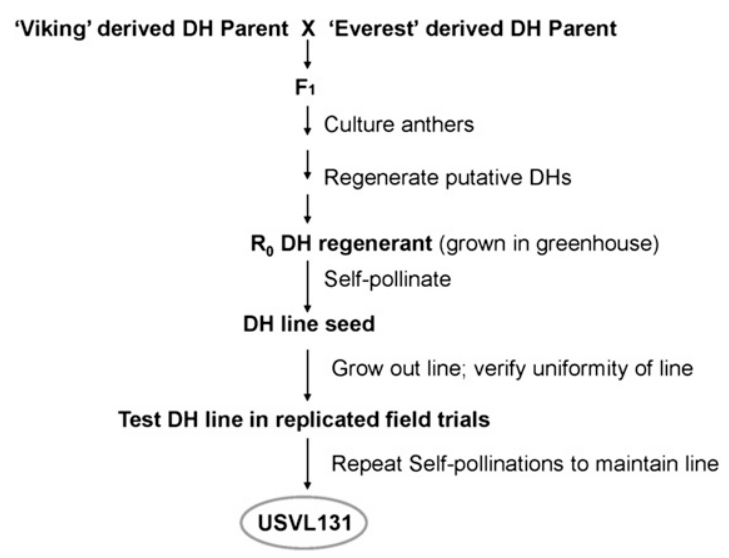

Fig. 1. Scheme followed in development of the doubled haploid (DH) inbred line USVL131. Original anther cultures were initiated in 1999. Essentially the same development scheme was used to generate USVL048; however, the $\mathrm{F}_{1}$ undergoing anther culture was the commercial hybrid 'Marathon', the parents of which are a trade secret and unknown. Original anther cultures leading to USVL048 were 
Table 1. Trait means for days from transplant to harvest (DTH), degree of dome (Dome) rating, bead size, head quality rating, head mass, and stem diameter for the inbred lines USVL048 and USVL131 and six control commercial broccoli hybrids in 2007, 2008, and 2009 fall environments at Charleston, SC, using growing conditions previously described (Farnham et al., 2011). ${ }^{\mathrm{z}}$

\begin{tabular}{|c|c|c|c|c|c|c|c|}
\hline Variety & $\begin{array}{c}\text { DTH } \\
\text { (days) }\end{array}$ & $\begin{array}{c}\text { Dome } \\
\left(\text { rating }^{y}\right)\end{array}$ & $\begin{array}{l}\text { Bead size } \\
(\mathrm{mm})\end{array}$ & $\begin{array}{l}\text { Head quality } \\
\text { (rating })\end{array}$ & $\begin{array}{c}\text { Head mass } \\
(\mathrm{g})\end{array}$ & $\begin{array}{l}\text { Stem diam } \\
(\mathrm{cm})\end{array}$ & Yr \\
\hline USVL131 & 85 & 1.7 & 1.65 & 4.4 & 191 & 32.2 & \\
\hline Liberty & 75 & 1.9 & 1.55 & 3.7 & 251 & 39.9 & \\
\hline Captain & 72 & 2.3 & 1.65 & 4.3 & 177 & 33.1 & \\
\hline Gypsy & 75 & 1.9 & 1.70 & 3.4 & 240 & 31.2 & \\
\hline Marathon & 89 & 1.7 & 1.63 & 3.8 & 252 & 36.0 & \\
\hline USVL048 & 97 & 2.1 & 1.58 & 4.2 & 161 & 28.0 & 2008 \\
\hline USVL131 & 87 & 1.6 & 1.56 & 4.0 & 186 & 30.6 & \\
\hline Liberty & 87 & 1.7 & 1.45 & 3.4 & 226 & 34.4 & \\
\hline Patron & 81 & 2.0 & 1.45 & 3.6 & 216 & 32.4 & \\
\hline Captain & 72 & 2.2 & 1.59 & 4.0 & 141 & 29.4 & \\
\hline Gypsy & 82 & 2.0 & 1.65 & 3.8 & 206 & 27.4 & \\
\hline USVL131 & 84 & 1.9 & 1.49 & 4.6 & 218 & 32.2 & \\
\hline Liberty & 79 & 2.0 & 1.30 & 3.8 & 246 & 37.8 & \\
\hline Patron & 77 & 2.1 & 1.31 & 4.2 & 243 & 37.0 & \\
\hline Captain & 61 & 2.1 & 1.63 & 4.5 & 173 & 31.3 & \\
\hline Gypsy & 66 & 2.1 & 1.53 & 4.2 & 272 & 36.5 & \\
\hline Marathon & 86 & 1.8 & 1.27 & 4.0 & 223 & 35.2 & \\
\hline Legacy & 86 & 2.0 & 1.23 & 3.7 & 272 & 37.9 & \\
\hline $\mathrm{LSD}_{0.05}$ & 5 & NS & 0.07 & 0.4 & 30 & 4.1 & \\
\hline
\end{tabular}

${ }^{\mathrm{z}}$ All field trials involved a randomized complete block design with three replications.

${ }^{y}$ Dome rating on a 1 to 5 scale with $1=$ very high dome, $3=$ moderate dome, and $5=$ flat.

${ }^{\mathrm{x}}$ Quality rating on a 1 to 9 scale with $1=$ exceptional, $3=$ excellent, $5=$ good, marketable $7=$ poor, nonmarketable $9=$ not recognizable as broccoli, nonmarketable.

wAnalysis of variance was conducted for each year using the three replications of data, and an LSD was computed if there was a significant $(P<0.05)$ genotype effect for a measured trait.

LSD = least significant difference; NS = nonsignificant.

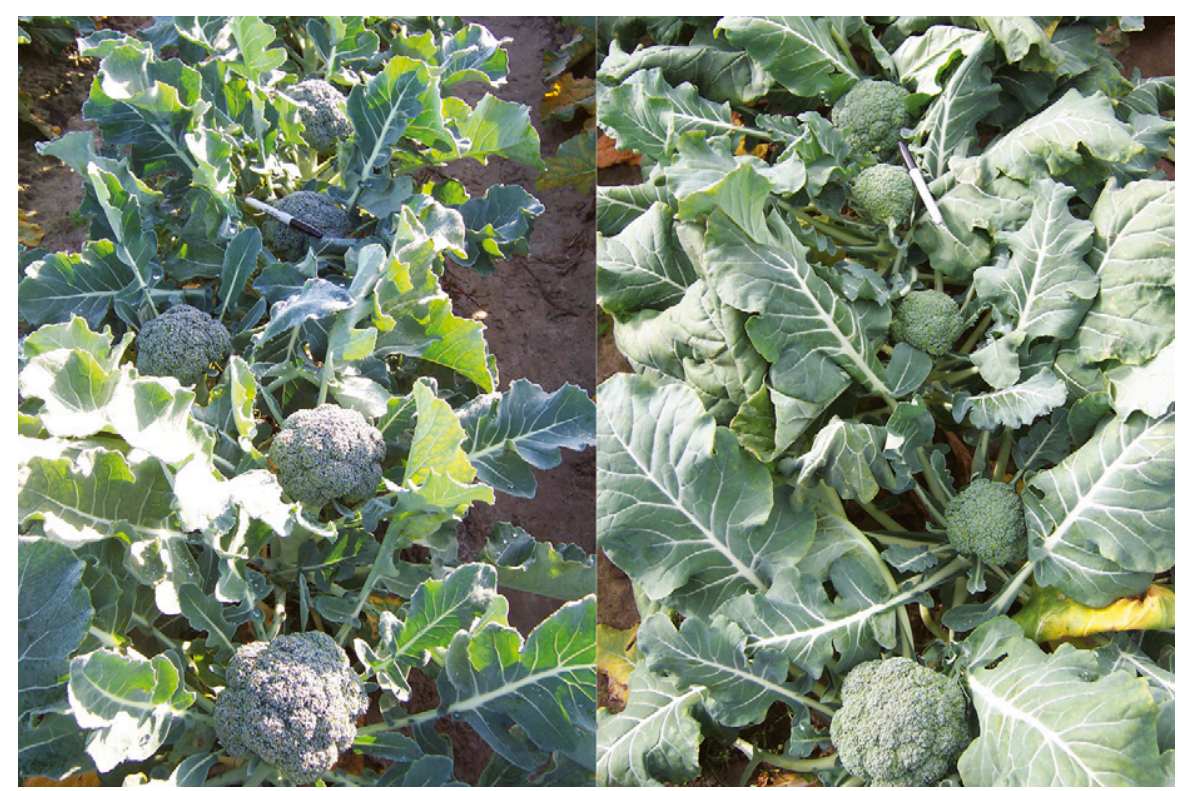

Fig. 2. Fall field plots of USVL131 (left) and USVL048 (right) grown at Charleston, SC, and showing heads at a mature, market-sized stage. Each photograph contains a standard Sharpie ${ }^{\mathrm{TM}}$ permanent marker (length is equal to $13.8 \mathrm{~cm}$ ) as a reference object for maturing heads. The length of the marker is close to the preferred head diameter $(\approx 12.5$ to $13 \mathrm{~cm})$ for crown-cut broccoli.

2007). Experience with USVL131 at the U.S. Vegetable Laboratory over the last 4 to 5 years indicates that it also exhibits excellent combining ability (unpublished data).
Small quantities of USVL048 and USVL131 seed produced by hand self-pollinations may be obtained from Dr. Mark W. Farnham, U.S. Vegetable Laboratory, 2700 Savannah
Highway, Charleston, SC 29414-5334. The genetic materials of this release will be deposited in the National Plant Germplasm System where they will be available for research purposes as well as for the development and commercialization of new cultivars. It is requested that appropriate recognition be made if either of these inbred lines contributes to the development of a new breeding line or hybrid.

\section{Literature Cited}

Abercrombie, J.M., M.W. Farnham, and J.W. Rushing. 2005. Genetic combining ability of glucoraphanin level and other horticultural traits of broccoli. Euphytica 143:145-151.

Farnham, M.W. 1998. Doubled-haploid broccoli production using anther culture: Effect of anther source and seed set characteristics of derived lines. J. Amer. Soc. Hort. Sci. 123:73-77.

Farnham, M.W., E.J. Caniglia, and C.E. Thomas. 1998. Efficient ploidy determination of antherderived broccoli. HortScience 33:323-327.

Farnham, M.W., A.P. Keinath, and M.A. Grusak. 2011. Mineral concentration of broccoli florets in relation to year of cultivar release. Crop Sci. 51:2721-2727.

Farnham, M.W., P.E. Wilson, K.K. Stephenson, and W. Jed. 2004. Fahey. Genetic and environmental effects on glucosinolate content and chemoprotective potential of broccoli. Plant Breed. 123:60-65.

Hale, A.L., M.W. Farnham, M.N. Nzaramba, and C.A. Collins. 2007. Heterosis for horticultural traits in broccoli. Theor. Appl. Genet. 115:351-360. 